\title{
大数据时代数字图书馆资源联合建设的共建共享
}

\section{Joint Construction and Sharing of Digital Library Resources in the Era of Big Data 周华强}

Huaqiang Zhou

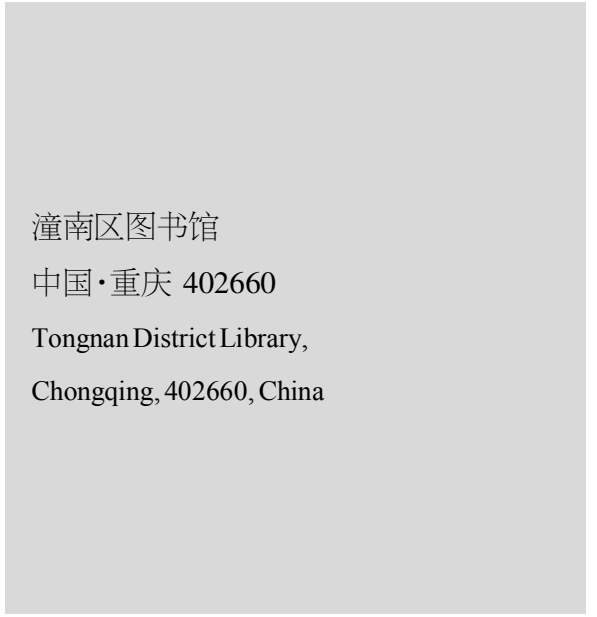

【摘要】在大数据时代, 中国各个地区的数字图书馆建设步伐越来越快, 为广大读者提供 了优质服务。根据读者的电子阅读需求、图书馆内部的知识资源, 建立现代化知识引擎服 务, 可以实现各地图书馆内部各项资源的共享, 为教学、科研工作的有效实施提供保障。

【Abstract】In the era of big data, the pace of digital library construction in various regions of China is getting faster and faster, providing high quality services for readers. According to the readers' demands for e-reading and the knowledge resources within the library, the establishment of a modern knowledge engine service can realize the sharing of all resources within the library, and provide guarantee for the effective implementation of teaching and scientific research.

【关键词】数字图书馆资源;联合建设; 共建共享

【Keywords】 resources of digital library; joint construction; co-construction and sharing 【DOI】10.36012/lcs.v2i1.1453

\section{1 引言}

在现代化社会的快速发展中，社会各界越来越注重大数 据的价值和应用, 在很大程度上推动着数字图书馆的发展。

\section{2 大数据时代的特点}

第一,信息数据资源丰富。互联网技术已在各个行业的发 展中得到了有效应用,现已广泛应用到人类生产、生产中,获 取了丰富的信息数据,实现了各项信息的共享。第二,数据结 构具有一定的复杂性,变化速度比较快,数据形式由传统的单 一模式转变成了多样化模式。在计算机技术水平快速提升的 大背景下, 数据形式在不断改变, 数据结构日益复杂, 如很多 数据以非结构化、半结构化形式存在。

\section{3 大数据时代数字图书馆建设的重要性}

在科学技术水平快速提升的大背景下, 各个国家越来越 注重学术资源建设工作, 国际相关研究开始全面研究数字图 书馆,收集、整理了一系列信息,并利用嵌入式技术,实现了数 字图书馆和数字化技术的有效融合, 这就使得数字化数据的 重要性日益突显。为了快速建设数字图书馆,管理部门需要注 重数字图书馆工作人员的服务质量，不断优化图书馆的服务 质量, 树立现代化服务理念, 实现数字图书馆的持续、稳定发 展。另外, 在大数据时代, 数字图书馆应用数字化技术, 有利于
发挥出传统图书馆数据的价值, 为读者阅读提供更多便利。

\section{4 大数据时代数字图书馆资源共享}

在现代化图书馆的建设中, 数字资源融合的本质是大规 模数据融合, 实现图书馆内部各项数据的融合, 其主要内容是 改变图书馆时间和空间的局限性, 将各项与图书馆相关的数据 和信息结合起来,形成完整的有机体,以此为基础做好各方面 的开发利用, 创造更多的价值。在大数据时代, 数字图书馆数据 表现为 “多源”, 有多个源头在不同方向针对同一对象进行数 据记录, 通过各项数据进行印证 [1]。除此之外, 数字图书馆资 源需要共享, 从而为数字图书馆的持续、稳定发展提供保障。

\section{5 大数据时代数字图书馆建设的新需求}

一方面, 国际数据环境发生了很大改变,数字图书馆面临 着新的挑战, 科学技术的发展需要大数据技术作为支持, 深入 分析现代化国际数字图书馆功能的变化, 推动数字图书馆的 建设步伐。在新时期的发展中, 数字图书馆建设已无法满足用 户的电子阅读需求, 用户获取的新资源越来越少, 尤其在知识 时代, 用户更乐于访问数字环境下的网络资源 ${ }^{[2]}$ 。另一方面, 科研方式发生了很大改变, 推动着数字图书馆的建设。数字图 书馆需要充分利用互联网技术的优势, 提升科研工作的整体 效率, 为数字图书馆建设、资源共享的有效性提供保障。

(下转第 34 页) 


\section{数字图书馆 Digital Library}

代的到来, 知识产权问题、资源保障等各个环节逐渐被社会各 方所重视, 然而当前的图书馆资源联盟无法满足如此庞大的资 源需求,如何对图书馆服务进行合理有效的全盘规划, 还需要 进行更为深人的研究探讨, 尽快实现图书馆资源的全面整合。

\section{1 .2 图书馆数字化服务质量不高}

目前来看, 各地图书馆资源内容千篇一律, 网站信息也基 本雷同, 没有自身的个性和特色, 也没有针对本地区专门设置 的需求量较高的内容, 在这个信息爆炸的时代,这类落后的图 书馆资源很难激起人们的兴趣。同时,大型图书馆建设大多在 省级或地市县级地区建设，乡村或社区用户几乎没有机会接 触，而乡村社区的基层图书馆建设迟滞落后，资源更新速度 慢, 大多数都为小说、娱乐书籍, 而具有足够权威性的科研类 资料几乎没有,基础资源严重不足。当前图书馆建设给用户的 感受仍然是很难找到所需资源, 这也正是大数据环境下, 图书 馆服务需要发展与创新的要点之一。

\section{2 大数据时代图书馆服务创新的对策}

3.2.1 利用大数据技术来构建图书馆服务的核心竞争力

大数据时代是一个信息爆炸的时代,网络技术、信息技术 飞速发展,带来的是各种信息数据爆炸式的增长, 同时用户获 取信息资源的渠道也更为丰富，甚至每天获取的信息资源数
量都是一个惊人的数字。

3.2 .2 构建大数据时代图书馆服务人才体系

大数据技术虽然早已形成, 但由于其海量的数据处理工 作和繁复的操作体系, 大数据技术的实际应用必须有专业的 技能型人才来推动, 不仅需要掌握大数据的操作体系, 更需要 掌握多个交叉学科的相关知识技能。因此, 要想实现图书馆大 数据化,首要的任务便是技术人才的挖掘和培养。

\section{4 结语}

随着大数据时代的来临, 海量信息资源的涌人为图书馆 服务带来的不只是机遇, 也有挑战。如何顺势发展, 将大数据 技术融合其中的同时留住用户，这双方面的要求才是图书馆 服务创新的主要工作。当前图书馆服务的创新仍停留在较为 粗浅的层面上,但笔者相信, 随着技术的发展, 图书馆服务体 系必将更加完善, 从而带给用户更好的服务体验。

\section{参考文献}

[1]王玉林,曾咏梅.图书馆大数据功能实现的障碍与对策研究 [J]. 情报理论与实践,2015(7):52-55+75.

[2]陈近,文庭孝.基于云计算的图书馆大数据服务研究 [J].图书 馆,2016(1):52-56+68.

\section{(上接第 32 页)}

\section{6 大数据时代数字图书馆资源联合建设}

\section{现状}

现阶段,中国图书馆发展过程中仍存在一系列问题,如信 息资源结构建设不合理、图书馆用户服务深度有待加深、图书 馆运营成本相对较高、图书馆资源整合能力有待提高等。同 时, 图书馆大数据分析技术应用中遇到了很多难题, 现代化数 字图书馆技术水平无法满足大数据时代的要求, 数字图书馆 设备、设施相对落后, 出现了明显的资源结构不合理、资源重 复等问题。另外,数字图书馆资源开发和共享不到位,未建立 完善的数字图书馆建设体系, 缺乏总体规划和宏观调控。

\section{7 大数据时代数字图书馆资源联合建设 的共建共享策略}

\section{1 发展新型数字知识服务}

在大数据时代, 图书馆需要树立现代化服务理念, 及时预 测用户的各项行为, 从大量数据中篮选出有效的信息, 提升用 户的服务满意度。除此之外, 数字图书馆建设具有一定的复杂 性、多变性、系统性特点,数字图书馆需要与企业、出版社等组 织进行合作, 深入挖掘大数据, 针对移动图书馆中的各项信息
资源提供增值服务, 以满足用户的知识服务需求。

\section{2 提高数字图书馆工作人员的服务意识}

在大数据时代,图书馆工作人员需要树立服务意识,为读 者提供更加优质的服务。同时, 在数字图书馆建设的过程中, 图书馆工作人员需要自觉维护知识产权, 提高人民群众的知 识产权法律意识。数字图书馆还需要充分发挥出数字化资源 的作用, 有效地维护各项信息和资源, 确保数字图书馆的持 续、稳定发展。

\section{8 结语}

综上所述, 为了提升数字图书馆的综合竞争实力, 图书馆 工作人员需要深人分析大数据技术, 强化数字图书馆服务功 能, 实现图书馆内部各项资源的共享, 为用户使用数字图书馆 提供便利。

\section{参考文献}

[1]杨强. 大数据时代下的数字图书馆信息安全问题探讨 $[\mathrm{J}]$.计算 机产品与流通,2020(3):91.

[2] 杨宁, 张志强. 科学大数据时代数字图书馆的新定位与新挑 战——第十六届数字图书馆前沿问题高级研讨班综述 $[\mathrm{J}]$. 图书与情 报,2020(1):127-135. 